\title{
FILOSOFÍA Y AXIOLOGÍA: PRIMERAS ANOTACIONES PARA UNA JUSTIFICACIÓN DE LA AXIOLOGÍA JURÍDICA
}

\author{
Urteaga Regal, Carlos Alberto (*)
}

"Ninguna rama de la Ciencia vive sin respirar Filosofía, pero esta necesidad es sentida por el Derecho más que por cualquier otra... el jurista se convence cada vez más de que, si no sabe más que Derecho, no alcanza a conocer siquiera el mismo Derecho."

Francisco Carnelutti

SUMARIO: Introducción 1. Algunas nociones propiamente filosóficas. 1.1. ¿La Filosofía es su historia?. La cuestión de su dependencia 1.2. Filosofía y Ciencia. Problemática de la delimitación II. Filosofía del Derecho y Axiología Jurídica. 2.1. Filosofía del Derecho. Nociones Previas y denominación. 2.2. Temas jusfilosóficos y Axiología Jurídica. - 3. Síntesis preliminar.

\section{Introducción}

Plantearse iniciar estudios en el terreno estimativo del Derecho, en tanto se intuye la hondura y radicalidad de los problemas que se plantea, nos lleva a graves cuestiones que parten por saber si estamos ante una Ciencia de la que ya se tiene claro su objeto y método, o si de lo que hablamos es de una disciplina que insiste en su debate y autonomía dentro de las fronteras de la Filosofía. En otros términos, tratase la Axiología de una ciencia particular, o no pasamos de una actividad propiamente filosófica cargada de sus notas propias en pugna y complementariedad.

Son estas preguntas, las que nos llevan a ensayar -aunque provisional- un primer paso exploratorio en la justificación del quehacer de nuestra disciplina. En ese itinerario, partir del presupuesto filosófico, significa ingresar -desde ya- en una cuestión propiamente filosófica, al ser necesario apuntar una noción de la filosofía, o en el mejor de los casos anotar una relación de puntos que se vinculen con su tarea. Y es en éste extremo que agilizamos un esbozo centrado en algunos caracteres, al que añadimos entre otras interrogantes a modo de hilo conductor: las que se refieren a la relación de la Filosofía con su historia; a ello, anexamos sumariamente el debate epistemológico sobre la delimitación de la Filosofía y la Ciencia. De aquí, pasamos a las nociones que giran alrededor de la relación entre la Filosofía del Derecho y la Axiología Jurídica. Temas inextricables, en suma, que si bien rebasan el marco de nuestro sucinto ensayo, se nos muestran urgentes como primer momento de reflexión, en el norte de nuestra inquietud centrada en una justificación, en lo posible exhaustiva, de la axiología o estimativa jurídica. 


\section{Algunas nociones propiamente filosóficas}

\section{1. ¿La Filosofía es su historia? La cuestión de su dependencia}

Cuestionarnos sobre lo qué es la Filosofía, significa ingresar -desde ya- en una cuestión propiamente filosófica, y desde aquí observamos el grado de libertad que respira la inquietud filosófica para llegar hacer problemática su propia actividad. No menos filosófico constituye, también, interrogarnos sobre la relación que guarda la Filosofía con su historia, es decir: ¿La Filosofía es propiamente Historia de la Filosofía? ¿Debemos tomar previsiones acaso sobre algunas concepciones historicistas que nos plantean esta identificación de la Filosofía con su historia? ¿Es posible hablar de una indagación filosófica al margen de las cuestiones históricas? ¿Es la Historia de la filosofía un momento del quehacer filosófico? ¿Cuándo nos encontramos con una actividad auténticamente filosófica?

Partiendo por la etimología del término Filosofía, expresión, formada por la reunión de dos voces griegas: "filos", que equivale a amor, y "sofía" que quiere decir sabiduría, tenemos que filosofía significa: "amor a la sabiduría". A su vez el término "sabiduría" comprende dos sentidos diferentes: de un lado significa cordura, sensatez; por otro lado, ilustración y conocimiento. De ahí que podamos desprender de este primer acercamiento con nuestro vocablo, la acepción que la entiende como "el amor a la sabiduría que nos capacita para ser cuerdos y sensatos en la vida y para comprender la esencia de la realidad."1 Lamentablemente, este camino no agota la riqueza de significaciones con que cuenta el término, y que fácilmente se advierten de una revisión de su historia, el mismo que pareciera poseer una "especie de plasticidad indefinida."2 Así, cada nueva acepción que adhiere al vocablo "Filosofía" aleja la posibilidad de una respuesta exhaustiva a nuestra interrogante.

En otros términos, si trasladamos la interrogante sobre lo qué es la Filosofía a quienes pensamos entendidos en la materia, resulta que nos topamos con opiniones tan disímiles, que fácil es concluir que Filosofía significa tanto como aquellos juicios y conceptos plasmados en la historia, o finalmente, "se diría, pues, que los entendidos no saben qué es Filosofía."3 Empero, el procedimiento histórico empleado por Dilthey parece adelantar una respuesta, a la inextricable cuestión, cuando considera como camino de solución la pauta marcada por aquellos filósofos que se han impuesto antes que otros a la conciencia de la humanidad y que, en consecuencia, han orientado el norte significativo de la Filosofía.4 O como señala Salazar B., es menester, una definición de tipo ostensivo, es decir, la filosofía es lo que su historia nos muestra, hay que tomar contacto con esta historia, familiarizarnos, para impregnarnos de su sentido.5 Sin embargo, la tarea extraordinaria que nos reclama este esfuerzo hacia una interpretación idónea de los planteamientos filosóficos, la pesquisa que constituye enfrentar el colosal panorama de teoría e ideas que los principales exponentes de la filosofía han delineado, enfrentase en su ensayo con una saludable acotación heideggeriana. Señala el profesor de la Universidad de Friburgo de Brisgovia, a propósito de la pregunta ¿qué es esto la filosofía?: "debemos tener presentes las definiciones anteriores y posteriores de filosofía. ¿Y luego? Luego discerniremos por una abstracción comparativa lo que es común a todas las definiciones ¿Y luego? Luego obtendremos una fórmula vacía que conviene a toda clase de filosofía. ¿Y luego? Estaremos tan alejados cómo es posible de una respuesta a nuestra pregunta."6 O lo que es lo mismo: "una cosa es examinar y describir opiniones de filósofos. Otra cosa muy diferente es discutir con ellos lo que ellos dicen, es decir, aquello de lo que ellos hablan.7 
Dejando pendiente el camino que nos reserva el historicismo, sus inconvenientes y observaciones, y ubicándonos en la interrogante de ¿si es posible hablar de una indagación filosófica al margen de la Historia de la Filosofía? Conviene anotar, que la independencia absoluta que exhibe o blande algún filósofo resulta pura ilusión en vista de la imposibilidad de evitar la sugestión del ambiente y época. Ningún filósofo puede hacer tabula rasa de los conocimientos e influjos recibidos en el proceso de su formación espiritual, aun cuando quiera reaccionar contra ellos, esta movido por sus exigencias.8 Un problema planteado adánicamente, sin precedentes y puntos de referencia, planeará inane e impertinentes en el vacío de su infertilidad.9

Reconocible la importancia de la Historia de la Filosofía, de la tradición, para la actitud filosófica; es menester, precisar que la Filosofía no se reduce a esa exclusiva tarea. Como bien advierte Miró Quesada C.: "La filosofía tiene carácter histórico; aunque no puede reducirse a su historia no puede practicarse sin estar referida a ella."10 Resulta palmario, entonces, la conveniencia de diferenciar, por un lado, aquel momento dedicado al sólo e importante esfuerzo reconstructivo, y por el otro, el esfuerzo, paralelo, que nos sujeta el paso en el camino del verdadero filosofar. Diferenciación para nada sencilla, en especial, para aquellas concepciones que sostienen que "La Filosofía es histórica, y su historia le pertenece esencialmente (...) La filosofía no se agota en ninguno de sus sistemas, sino que consiste en la historia efectiva de todos ellos."11 $\mathrm{Si}$ bien es innegable la importancia de la tarea reconstructiva para la faena filosófica. No menos importante es saber, cuando hablamos de verdadera filosofía, para no caer en un mero examen o descripción de opiniones de filósofos como observa Heidegger. Así parece notarlo R. Mondolfo, cuando desde su concepción historicista plantea que "aun recibiendo y padeciendo el influjo de sus antecesores, cada filosofo que haga verdadera filosofía y no quiera ser simple repetidor de lo que han dicho otros, reacciona a su influjo de una manera personal, distinta de individuo a individuo."12

Y sobre una noción identificadora de una auténtica filosofía, las afirmaciones de los pensadores griegos nos indican una senda. Baste señalar lo que decía el Estagirita: "los hombres comienzan y comenzaron a filosofar movidos por la admiración; al principio, admirados ante los fenómenos sorprendentes más comunes; luego avanzando poco a poco y planteándose problemas mayores, como los cambios de la luna y los relativos al sol y a las estrellas, y la generación del universo."13 Es decir, la Filosofía desde la antigüedad Griega no partió de un diálogo salido de la nada, partió de una motivación debido a algo, partió de un asombrarse ante algo. En la misma dirección, enrolase, también, Heidegger, cuando afirma que el asombro sostiene y domina a la filosofía, y es más, predomina en cada paso de la filosofía.14 Lamentablemente, este origen de la filosofía, se ha dejado al margen, la admiración, o asombro ante algo, simplemente ya no se menciona. La historia de la Filosofía en su identificación con la Filosofía, ha contribuido a asfixiar este rasgo imprescindible del verdadero filosofar.

Apreciase, por tanto, que el asombro o perplejidad, se revela como un rasgo filosófico que nos permite reconocer si nos encontramos ante una actitud, palpitante, propiamente filosófica. Y aquí, es oportuno mencionar "que hay admiración y admiraciones. Hay la admiración de cualquiera y la otra, la contraria, como dice Aristóteles, que es la filosófica. Un espíritu simplón puede pasarse la vida extrañándose de las cosas más banales y corrientes sin llegar nunca a filosofar (...) La admiración de que se nutre la filosofía es, pues, una manera de ver y pensar aprendida en la escuela de los filósofos." Empero, cabe agregar que "Aprender y educarse en filosofía no significa recibir simplemente contenidos teóricos, sino asumir problemas y prepararse para responderlos de un modo original." En otros 
términos: “(...) aprender, filosofía no es repetir una filosofía existente, sino llegar, por mediación de un filosofar existente, a un nuevo pensar."15 Filosofar, no se constriñe, pues, al mero aporte de escuela, al desvinculado logro de una exhaustiva interpretación, y desvitalizante registro, hasta ahí, ni siquiera hemos completado el primer paso del quehacer denominado filosofar.

Así, al asombro adicionase, otra categoría fundamental, la originalidad, la que inclusive debe subrayarse, en vista del descuido de la perspectiva histórica para atender este lado de naturaleza creadora y libre que, en absoluto, procura estacionarse en un mero registro pasivo y exacto de lo que otros han hecho, sino al contrario que busca entablar un diálogo provechoso, acorde con lo que se discute como de lo que planteamos como problema.16 Todo acercamiento con la historia de la Filosofía que deje fuera a los citados rasgos, no realiza propiamente filosofía.

Ahora bien, este escueto esbozo alrededor de una noción de la filosofía, que nos aclare respecto de la vinculación con la disciplina que se ocupa de su historia, estaría incompleto, si es que no apuntamos, otra nota fundamental, que fácilmente se desprende de lo expuesto. Nos referimos, al quehacer íntimo, vivencial, del filosofar. Al respecto, subraya el profesor Fernández Sessarego: "La filosofía no es algo ya acabado con lo cual nos tropezamos. Ella comporta permanente actividad; insosegable tarea. Las 'doctrinas filosóficas' son tan sólo el resultado, el producto, del filosofar."17 Coincidente, anota García Morente: "la filosofía, más que ninguna otra disciplina, necesita ser vivida. Necesitamos tener de ella 'vivencia'."18 Para este rasgo vital del filosofar, oportuna, resulta, también, la expresión orteguiana: "la doctrina filosófica, eso que está o puede estar en libros, es solo la abstracción de la auténtica realidad "filosofía" -es solo su precipitado y su cuerpo semimuerto (...) el ser de la filosofía es lo que hace el filósofo, es el filosofar una forma del vivir." "Todo lo que no sea definir la filosofía como filosofar y el filosofar como un tipo esencial de vida es insuficiente y no es radical."19

Si bien no hemos pretendido agotar en tan breve apartado tema tan complejo como este de la relación de la Filosofía con su historia, el sólo plantearnos inicialmente la cuestión, nos permite ordenar algunos puntos. Así, en resumen, descubrimos que sin asombro la vivencia filosófica se nos escapa. Además, apreciamos que sumada a la tradición filosófica es menester la independencia y originalidad. En otros términos, la verdadera actitud filosófica, requiere de la tradición que nos descubre la Historia de la Filosofía y de la independencia del filosofar, éste último rasgo unido a la admiración salvaguardan el pulso vital del filosofar. Conviene, pues, dar a la Historia de la Filosofía su justa dimensión en relación con el filosofar.

\subsection{Filosofía y Ciencia. Problemática de la delimitación}

Una rápida mirada a algunos planteamientos que sobre la problemática delimitadora se han dado nos permite entrever inicialmente un sector conformado por aquellos que pretenden la reducción o conversión de la Filosofía a la Ciencia; y, por otro lado, desde la orilla opuesta, aquellas posiciones que nos plantean la diferenciación entre ambas tareas. En la primera posición, se encuentra la expresión kantiana: "Así, pues, la crítica (refiriéndose a la Crítica de la razón pura, anot. nos.) contiene en sí, y aún ella completamente sola, el plan completo, bien probado y garantizado, y hasta todos los medios de realización en sí, por los cuales puede ser realizada la metafísica como ciencia; por otros caminos y otros medios es imposible."20 De igual modo, desde su posición, Husserl nos dice que los intereses más elevados de la cultura humana exigen el desarrollo de una filosofía rigurosamente científica y sólo en ese sentido se justifica un cambio.21 Positivistas lógicos como Wittgenstein, desde 
éste mismo lado, sostiene, "El verdadero método de la filosofía sería propiamente éste: no decir nada sino aquello que se puede decir; es decir, las proposiciones de la ciencia naturalalgo, pues, que no tiene nada que ver con la filosofia(...)”[22]

Por su parte, la voz renuente a la conversión filosófica, cuenta entre sus partidarios a Karl Jaspers, para él, la Filosofía es "menos que ciencia y más que ciencia”. En vista de que la filosofía va más allá de lo objetivo". Es menos que ciencia porque no alcanza ningún resultado demostrable, que se imponga con validez objetiva a todos los investigadores. Pero es más que ciencia porque es fuente de una verdad inaccesible a la búsqueda científica.'[23] Zubiri refiere que la diferencia radical que separa a la filosofía y a las ciencias no procede del estado del conocimiento científico y filosófico, la cuestión sobre la existencia del objeto de la filosofía es lo que radicalmente escinde a la filosofía de todas las demás ciencias. "Mientras que estas parten de la posesión de su objeto y de lo que se trata es simplemente de estudiarla, la filosofía tiene que comenzar por justificar activamente la existencia de su objeto, su posesión es el término y no el supuesto de su estudio, y no puedo mantenerse sino reivindicando constantemente su existencia."'24] Aquí, añadimos a Karl R. Popper, conocida es su expresión "Llamo problema de la demarcación al del encontrar un criterio que nos permita distinguir entre las ciencias empíricas por un lado, y los sistemas metafísicos por otro.’[25]

A nuestro primer planteo del debate demarcador, podríamos incluir la posición bungeana que considera innecesaria la demarcación de Popper. Según M. Bunge, "toda investigación científica supone principios filosóficos; además, toda filosofía que se pretenda científica recoge resultados de la investigación científica". "La ciencia se solapa parcialmente con la filosofía."[26] "A la difícil problemática, le podemos añadir otras aristas, verbigracia: la distinción observación/teoría defendido por la epistemología tradicional, que sostiene que es absolutamente necesario que los hechos sean independientes y previos a las teorías y que su status ontológico no dependa de ellas[27]; la cuestión de la "variación de significado"[28], entre otros temas que, a decir de Quintanilla Pérez-Wicht, nos sugerirían un nuevo viraje en la agenda epistemológica. De un monismo metodológico pasaríamos a hablar de un pluralismo, consecuencia y rechazo de la tradición cartesiana, en el que la pregunta por la demarcación se torna poco atractiva. Aquí, la pregunta por la cientificidad, debe abandonarse y debe ser reemplazada por las preguntas: ¿Qué hace que una teoría sea mejor que otra? y ¿qué criterios deberíamos utilizar para escoger una teoría cuando se produzca un conflicto de teorías?.[29]

Ahora bien, anotada hasta aquí de manera sintética la cuestión demarcadora, en el que se ha presentado, entre otros aspectos, los inconvenientes de las divisiones radicales, así como la crítica al monismo metodológico subyacente en la pretensión de la interrogante. Corresponde, rápidamente, ingresar en el examen de algunos caracteres del quehacer filosófico en parangón con aquellas notas que parecen identificar mejor la actitud científica. Una nota patente de la actividad filosófica lo constituye la aspiración universalista. En tanto procura soluciones últimas, la Filosofía orientase hacia la totalidad de las cosas, por su parte, las ciencias se caracterizan por tener como objeto parcelas de la realidad. Totalidad filosófica en la que -como apreciamos- se incluye la propia ciencia como tema de indagación. En contraste, pues, se revela la actitud del especialista, cuya mirada se dirige a un sector mayor o menor de la totalidad de los objetos del conocimiento[30], situación, que a decir de Mario Bunge, se trataría del tercer componente de su decatupla conceptual de la ciencia, referido al Dominio(D), y que vendría a ser el universo del discurso o clase de referencia, en otras 
palabras, se trata del conjunto de ideas o de hechos, a los que se refieren o que estudian los miembros de la comunidad científica.[31]

Asimismo, el enfoque sintético de la Filosofía, característico de su actividad, diferenciase de la perspectiva analítica de la ciencia. La ciencia como cuerpo de conocimientos o de enunciados, requiere ser interpretada, fundamentada, equivale a adscribirle un sentido, tarea que es obra de la filosofía. [32] Señala Oscar Miró Quesada (Racso): "Las diversas ciencias nos ofrecen, pues, perspectivas parciales del mundo, la filosofía es una visión de conjunto; es el panorama de la totalidad. En resumen: la ciencia es una explicación analítica de las cosas; la filosofía es una interpretación sintética de la realidad.'[33] Además, en tanto cuestionamiento radical, la Filosofía no se detiene ante supuestos, ni métodos, su inquietud la lleva a una problematización constante. Nos encontramos ante un punto de vista del límite, de los aspectos fundamentales, donde las ciencias se dan por satisfechas y dan mil cosas por supuestas, allí empieza la tarea filosófica, el preguntar del filósofo. En otros términos: "Las ciencias conocen; él pregunta qué es conocer. Los otros sientan leyes; él se pregunta qué es la ley. El hombre ordinario habla de sentido y finalidad. El filósofo estudia qué hay que entender propiamente por sentido y finalidad (...) Donde las otras se dan por satisfechas, la filosofía sigue preguntando e investigando." Radicalidad del punto de vista, que alcanza al método, así, "el filósofo no tiene por qué limitarse al método empírico, reductivo. Puede también valerse de la intuición del dato y de otros medios." [34]

Retomando las notas de universalidad y síntesis filosófica, provechoso resulta lo que bien ha puesto en claro Ortega y Gasset, para quien la universalidad no es otro que el momento de cara al universo, de tensión opuesta, que se plantea el principio metódico y autonómico que se propone la filosofía, que si bien no cuenta con disciplinas autónomas ella por sí misma en su afán de verdades primarias, procura autonomía, renuncia a apoyarse en nada anterior a la filosofía misma. Advierte el filósofo español, "Ese punto o puntos mínimos de verdad rigorosa tienen que ser elásticamente dilatados hasta aprisionar cuanto hay. Frente a ese principio ascético de repliegue cauteloso que es la autonomía actúa un principio de tensión opuesta: el universalismo, el afán intelectual hacia el todo, lo que yo llamo pantonomía.’[35]

Antes de finalizar nuestro sumario apartado, apuntamos un carácter más acerca de la filosofía, aunque no exclusivo de su quehacer, y que nos pone en contacto, a decir de Ortega, con el sentido prístino de su calidad significativa, con su primer aliento, acorde, con su nombre primigenio. Nos referimos al vocablo a-létheia, entendido, como averiguación, hallazgo de la verdad desnuda tras los ropajes de falsedad que la contaminaban. Alétheia, como dice el filósofo español, significa "verdad", y la "verdad" debe comprenderse no como cosa muerta, según veintiséis siglos de habituación e inercia, "sino como un verbo-«verdad» como algo viviente (...) en suma, como acción.”[36] Atinadas expresiones inclusive, para los actuales tiempos de cómoda y resignada "astenia en el ataque al problema de la verdad". Contexto, pródigo en acepciones nihilistas ajenos al término escepticismo, o mejor dicho al skeptikoí propio de los griegos.[37] En este punto, la filosofía es, pues, incoercible búsqueda, vocación perescrutadora, de la verdad.

Apuntada -provisionalmente- la presente relación de algunos caracteres, no creemos haber trazado una línea definitiva, sino que más bien hemos atisbado un saludable grado de diferenciación que no busca desatender la complementariedad existente entre ambos quehaceres del saber. De aquí es sencillo vislumbrar, para la relación Filosofía y Ciencias del 
Derecho, ese contacto. Para Cossio, el verdadero jurista no puede perder el contacto con la Filosofía del Derecho porque ésta le resulta indispensable para poder hacer verdadera ciencia. En efecto, las cuestiones epistemológicas nos coloca a buen recaudo de posiciones extremas. Como anota el profesor argentino, la Ciencia no se estudia a sí misma, la Ciencia se dirige a las cosas, en tanto que la Filosofía se dirige a la Ciencia, la considera como a una cosa y la explica en su posibilidad y sentido. [38]

\section{Filosofía del Derecho y Axiología Jurídica}

En este apartado de nuestro estudio, se presentan como tareas -pendientes- la de saber la relación que guarda la disciplina axiológica con la Filosofía del Derecho, en esa dirección, resulta pertinente, entre otras cuestiones, interrogarnos: ¿Significa la Filosofía del derecho una disciplina particular de la Filosofía? ¿Se trata de una disciplina jurídica o filosófica? ¿Se puede hablar de una problemática estimativa en el ámbito jurídico? ¿Se justifica la perspectiva filosófica sobre tales asuntos?

\subsection{Filosofía del Derecho. Nociones previas y denominación}

La vinculación que podamos encontrar entre la Filosofía del Derecho y la Axiología Jurídica, parte primero por aclararnos respecto a la relación que guarda la filosofía y la actividad jusfilosófica: ¿Se trata de una relación intrínseca e indisoluble? ¿Significa una disciplina especializada de la Filosofía?. Si partimos por considerar la pretensión de saber universal como nota ineludible del filosofar y a ello sumamos la vocación integradora de su actividad, es sencillo concluir que no existen disciplinas independientes o especializadas en el caso de la Filosofía. Anota bien Recaséns Siches, cuando al referirse a la Filosofía como conocimiento del universo, de todo cuanto hay, no lo presenta como suma o compendio de todos los conocimientos sobre todas las cosas, sino como "apetito de integridad que no se para en trozos secundarios, ni en acumulación de visiones parciales-cuales son las de la ciencia.'[39]

La Filosofía del Derecho no es otra que la misma Filosofía que sin perder su vocación de universalidad, se proyecta al mundo jurídico. [40] Como observa López de Oñate considerar a la Filosofía del derecho una parte o sección de la filosofía en general, significaría introducir un concepto impropio, en razón de que la Filosofía está toda en cada una de sus indagaciones, y no puede distinguirse en partes por decir así autónomas.[41]

En lo que respecta a la denominación "Filosofía del Derecho" para nuestra disciplina, no hay objeción para su acertada expresión, a todas luces apropiada. Su claridad, evita prejuzgamientos o adelantos respecto del contenido que se desarrolla o solución que se plantea. Lo que no sucedía con las denominaciones acuñadas por los positivistas, y escuelas de derecho natural. Cogliolo y Austin, por ejemplo, la llamaban: 'filosofía del derecho positivo', o 'filosofía de la ley' o 'filosofía jurídica'.[42]

La Filosofía del Derecho, por tanto, no se trata de una disciplina jurídica, mucho menos de una parte o sección de la filosofía. La Filosofía del Derecho no es otra que la Filosofía ocupada desde una vocación integral y radical en las cuestiones jurídicas. Acertado, anota, el jusfilósofo de São Paulo, Miguel Reale: "La Filosofía del Derecho no es propiamente una disciplina jurídica, sino que es la misma Filosofía en cuanto dirigida hacia un ámbito de la realidad, cual es el de la realidad jurídica. Tampoco puede afirmarse que sea una Filosofía especial, porque es Filosofía en su totalidad, en la medida en que se 
preocupa por algo que posee valor universal(...)Dondequiera que exista el hombre, alli existe el derecho como expresión de vida y de convivencia. La Filosofía sólo se ocupa de aquello que tenga sentido de universalidad (...) Con ello se ponen de manifiesto los títulos que justifican la existencia de una Filosofía jurídica.'[43]

\subsection{Temas Jufilosóficos y Axiología Jurídica}

Siendo la Filosofía del Derecho la misma Filosofía ocupada en la problemática jurídica resulta explicable que los rasgos que identifican su actividad alcancen, también, a los trabajos jusfilosóficos; y no sólo ello, el conjunto siempre abierto de la problemática filosófica deja su impronta, se proyecta en las indagaciones jusfilosóficas. Y entre esas cuestiones primordiales que avivan su tarea se encontrarían las preguntas sobre la temática axiológica. La interrogante alrededor de los valores/encuentra, así, su espacio problematizador en la Filosofía del Derecho, en el ámbito, apropiadamente denominado Axiología o Estimativa Jurídica, un rápido repaso de la tradición jusfilosófica, lo sale comprobando. Sin embargo, no sería el único problema que encuentra su entroncamiento con la tarea jusfilosófica.

Entre los temas centrales de la Filosofía que inquietan y despiertan desarrollos en los estudios jusfilosóficos tenemos a la Gnoseología. [44] Aquí la filosofía, según Bochenski, se orienta a estudiar la posibilidad del conocimiento mismo, los presupuestos y límites del conocimiento posible. La Filosofía del Derecho no escapa al influjo de la problemática del conocimiento, así por ejemplo, se aprecia en el caso de la obra de R. Stammler quién siguiendo las huellas del pensador de Königsberg renueva la perspectiva jusfilosófica, diciéndonos que la misión del derecho, aparte de desenvolver el concepto del Derecho y ver cómo aparece en la vida humana, se encarga de enseñar en qué consiste la justicia. La noción de la justicia nace de la posibilidad de armonizar en nuestra mente de un modo absoluto todas las aspiraciones concebibles. [45] Desde la concepción de Vanni, nos encontraríamos aquí en una de las tres investigaciones de la Filosofía del Derecho, es decir, la "indagación crítica" relativa al saber jurídico, que pregunta por el fundamento y las condiciones que debe cumplir la ciencia jurídica para estar seguros de la validez y legitimidad de sus resultados.[46]

Apreciando la preeminencia ontológica de la pregunta que interroga por el ser, Heidegger, repara que el preguntar ontológico es anterior al preguntar óntico de las ciencias positivas. En tal sentido, apunta el pensador alemán, resulta ingenuo y no deja "ver a través" de él cuando su andar indagando tras del ser de los entes deja por dilucidar el sentido del ser en general. [47] De ésta forma, Heidegger, gesta la oscilación del péndulo filosófico hacia la problemática del ser; no de éste o aquel ser concreto y determinado, sino del ser en general, del ser en la más vasta y amplia acepción de esta palabra. Por consiguiente, el problema comprendido en la teoría del ser será justamente: ¿qué es el ser?.[48] Desde éste ángulo es posible, también, una aproximación a los planteamientos jusfilosóficos que apoyados en una concepción ontológica nos alcanzan una respuesta sobre la naturaleza del Derecho. Al respecto, subraya el profesor Fernández Sessarego: "El tema primario de la Filosofía del Derecho es el ontológico, la pregunta por su objeto. Hay que reivindicarle a la ontología jurídica esta primariedad -al par que la tiene la ontología en la filosofía-frecuentemente olvidada."[49].

En cuanto a la Axiología o Estimativa, anota R. Frondizi, tenemos a una disciplina que madura sus primeros pasos en la segunda mitad del siglo XIX. Si bien, algunos valores inspiraron hondas reflexiones a más de un filósofo de la antigüedad, empero, tales esfuerzos 
no lograron cuajar en una región propia, sino que cada valor recibía un tratamiento aislado. Es decir, no alcanzaron avizorar un planteamiento más íntegro del problema. De ahí, la necesidad de una indagación, crítica, orientada a despejar, el denso y confuso marco teorético estimativo, que deja, similar a las otras ramas filosóficas, su impronta ineludible en el ámbito jurídico. Así se abre paso, la necesidad de abordar, entre otras urgentes y graves cuestiones, las que inquieren: en la naturaleza del valor; la mostración de sus categorías fundamentales; las que se preocupan por la vía metodológica acorde con su objeto; las que se plantean el detalle de la jerarquía, y plexo de valores; la existencia o no de su autonomía; sobre sus implicancias en el terreno de otras disciplinas. Huella de la presencia estimativa, que directa o indirectamente han sido parte de las disquisiciones jusfilosóficas y axiológicas del Derecho, conforme pasaremos a ver en escueto y parcial estudio.

Recaséns Siches, desde su posición, fundamenta la importancia de la Estimativa Jurídica, al extremo de señalar que sin su presencia sería imposible la existencia del Derecho Positivo: "para que pueda existir una norma de Derecho positivo, precisa que antes se haya producido una estimación, la cual entonces no es todavía Derecho positivo y sobre la cual se fundará el Derecho positivo que se dicte después. La norma positiva constituye la expresión de un juicio de valor. Sin valoraciones no cabría la existencia del Derecho positivo. Por tanto, los ingredientes del Derecho positivo no son todos ellos positivos, sino que hallamos la referencia intencional a algo no positivo."[50] Hans Kelsen pese a su positivismo, no deja de alcanzar una respuesta al tema estimativo, aunque sea sólo para sostener, que la justicia absoluta es un ideal irracional que escapa al conocimiento racional. La ciencia del derecho, afirma, sólo puede explorar el dominio del derecho positivo. Apunta el jefe de la Escuela Vienesa: "la ciencia del derecho no puede declarar que tal orden -o tal norma jurídica- es justo o injusto, pues tal juicio se funda, ya sea en una moral positiva (...), o en un verdadero juicio de valor, con carácter subjetivo. (...)Más aún, la historia del espíritu humano que se esfuerza en vano desde hace siglos en resolver este problema, muestra que la justicia absoluta no puede ser definida racionalmente. Dotada de una validez absoluta, la justicia está más allá de toda experiencia, como la idea platónica está más allá de la realidad sensible y la cosa en sí es trascendente a los fenómenos."[51]

Desde la división de la Estimativa Jurídica en pura y positiva, Carlos Cossio, manifiesta que nuestra disciplina es el reconocimiento del Derecho en tanto que es valor, es decir, en tanto que es orden, seguridad, poder, paz, cooperación, solidaridad, y en última instancia, justicia.[52] Para el Profesor Fernández Sessarego, la Estimativa Jurídica, se ocupa de los valores jurídicos, su jerarquía y conexiones, su cumplimiento o incumplimiento, y cobra unidad a través del plano ontológico, desde que toda conducta por ser tal es valiosa o desvaliosa y toda norma como pensamiento se refiere necesariamente a su objeto peculiar.

Todo valor exige una conducta que lo realice y todo pensamiento un objeto pensado. [53] De Francisco Miró Quesada C., conocido es su ensayo Sobre el Derecho Justo en el que, apoyándose en el apriorismo formalista kantiano, y planteándose la respectiva depuración de los rezagos de ética material, sostiene: "que la única condición que debe cumplir una acción para que sea racionalmente ética, es que no sea arbitraria. De aquí se sigue que el Derecho justo, es decir el sistema legal que permita la forjación de una sociedad éticalo lo que es lo mismo, racional o justa), es el que hace imposible la existencia de la arbitrariedad en la vida social." [54] En otro momento de su investigación, y respaldándose en la teoría de las relaciones, define la simetría como condición suficiente de la justicia de una ley. Concluyendo que "Una ley es justa si es no arbitraria y simétrica."[55] 
Incluso entre aquellos que se han convertido en la crítica contemporánea más severa a la tradición positivista, encontramos la problemática axiológica; es el caso de Dworkin, que manifestando un apartamiento de las posiciones sostenidas por Kelsen, Ross y Hart, entre otros, cuestiona la tesis de la separabilidad de derecho y moral desde el punto de vista de la decisión judicial.[56] El argumento dworkiniano, anota: que en los casos más difíciles o duros los jueces resuelven acudiendo a estándares que no son normas jurídicas, a las que se identifican como principios, definidos estos últimos como el estándar que ha de ser observado porque es una exigencia de justicia, equidad o alguna otra dimensión de la moralidad.[57] Desde la vertiente kantiana, Rawls considera a: "La justicia como la primera virtud de las instituciones sociales, como la verdad lo es de los sistemas de pensamiento. (...) no importa que las leyes e instituciones estén ordenadas y sean eficientes: si son injustas han de ser reformadas o abolidas. Cada persona posee una inviolabilidad fundada en la justicia que ni siquiera el bienestar de la sociedad en conjunto puede atropellar."'[58] Entre los representantes de las teorías éticas contemporáneas, sobresale Alasdair Macintyre. Analizando las posturas de Rawls y Nozick, sostiene este autor, que para ambos pensadores, "una sociedad se compone de individuos, cada uno con sus intereses, que han de avanzar juntos y formular reglas de vida comunes (...) en ambas interpretaciones, los individuos son primordiales y la sociedad de orden secundario". En el caso de Rawls -expresa- se presenta un principio de igualdad respecto de las necesidades. Nozick, en cambio, estima primero lo que es un principio de igualdad con respecto al derecho. Para Rawls es irrelevante cómo llegaron a su situación actual los que ahora se hallan en grave necesidad; la justicia es asunto de modelos presentes de distribución, para los que el pasado es irrelevante. Nozick, sólo cuenta títulos de lo legítimamente adquirido en el pasado; los modelos presentes de distribución deben ser irrelevantes en sí mismos para la justicia. "Rawls y Nozick expresan con mucha fuerza la opinión muy extendida que ve la entrada al mundo social, por lo menos idealmente, como acto voluntario de individuos potencialmente racionales, con intereses previos, que tienen que hacerse la pregunta: ¿en qué tipo de contrato social con los demás es razonable que entre? Nada tiene de extraño que a consecuencia de esto sus opiniones excluyan cualquier interpretación de la comunidad humana y a la persecución de los bienes compartidos, pudiera proporcionar la base para juicios acerca de la virtud y la injusticia.”[59]

A nuestro sucinto y parcial repaso, hay que añadir, como aclaración -que se infiere, además, de lo expuesto-, que los jusfilósofos como se comprueba, no hacen de su quehacer cajones cerrados, no hay para algunos de ellos disciplinas filosóficas soberanas. En Cossio, por ejemplo, la importancia el tema gnoseológico, no resta espacio, para una aguda perspectiva ontológica, e incluso axiológica, como pasaremos a ver. En otros términos y como bien abrevia Ortega: "los problemas radicales están inexorablemente ligados unos a otros, y tirando de cualquiera salen los demás."

Se desprende, entonces, de nuestro escueto recorrido, la imbricación y proyección de la intrincada temática axiológica en la esfera del Derecho. Sobre esta influencia de la filosofía de los valores en el ámbito jurídico, se aprecia, que con el descubrimiento de los valores, la Estimativa Jurídica amplía considerablemente su campo. Al lado de la justicia presentase una vasta zona de valores que interesan al Derecho. Las perspectivas que se abren a la Estimativa son considerables, al ampliarse su horizonte de especulación. [60] Ahora bien, hay que precisar de una vez, que la interrelación e importancia que podemos encontrar entre los estudios estimativos y el Derecho no se dan sólo desde la dirección filosófica, sino que, además, el sentido provechoso parte también de la compleja problemática jurídica. Así lo entiende Ascoli cuando expresa: "aun los juristas más ciegos para la perspectiva filosófica, 
han reconocido que la ciencia del Derecho positivo desemboca en la filosofía en tres momentos: con las lagunas del orden jurídico, con la interpretación de la ley y con los principios generales del Derecho.'[61]

Finalmente, añadimos, que las razones para estar conformes con la denominación de 'Axiología' o 'Estimativa Jurídica' para nuestra disciplina, se asemejan al caso de la Filosofía del Derecho, en tanto, evita prejuzgamientos o adelantos sobre el contenido o tarea que se plantea. [62] La palabra Estimativa como expresión global de todos los estudios sobre los valores, fue empleada originariamente por José Ortega y Gasset en 1924 en su artículo "¿Qué son los valores? Una introducción a la estimativa" (Revista de Occidente, Madrid, núm. 4), denominación prontamente aceptada e incorporada de modo general a nuestra terminología filosófica.[63] En cuanto al término Axiología, formado a base del término griego axios ("valioso", "estimable", "digno de ser honrado"), fue J. N. Finlay (Axiological Ethics, 1970) quien hace notar que Wilbur M. Urban, en su texto Valuation: Its Nature and Laws (1906), fue el primero en usar «axiología» para traducir la expresión alemana Wertheorie ("teoría del valor") que el economista Von Neumann había introducido en economía, como «teoría del valor económico», y que Ehrenfels y Meinong, entre otros, habían tratado como teoría general de todos los valores.[64]

\section{Síntesis preliminar}

Sumariamente anotamos, adónde nos ha llevado - muy preliminarmente- nuestro itinerario alrededor de una justificación axiológica jurídica, para empezar, observamos:

1) La problemática de la delimitación de la Filosofía y la Ciencia, así como la referida a la relación de la Filosofía con su historia, y sabiendo que no hacemos más que empezar un primer tanteo sobre cuestiones centrales que han ocupado y ocupan a la actividad filosófica, nos muestran, su relevancia e ineludible vinculación dentro de las interrogantes que se abren paso en nuestra introducción a la Estimativa Jurídica. Así, descubrimos algunos caracteres que permiten identificar el quehacer filosófico orientado al estudio de los valores, denominado acertadamente Axiología o Estimativa, y que para el caso del Derecho, en cuanto a su estudio y tratado lleva el nombre de Axiología o Estimativa Jurídica. En síntesis, y sin pretender agotar tema tan intrincado como éste de la vinculación de la Filosofía y su historia, el sólo plantearnos inicialmente la cuestión, nos ha permitido ordenar algunos puntos, a saber: Que sin genuino asombro la vivencia filosófica se nos escapa(I). Además, apreciamos que sumada a la importancia de la tradición filosófica(II), es menester la independencia y originalidad(III). En otros términos, la verdadera actitud filosófica, requiere de la tradición que nos descubre la Historia de la Filosofía y de la independencia del filosofar, éste último rasgo unido a la admiración salvaguardan el pulso vital del filosofar. El esfuerzo filosófico no se constriñe a la órbita de su historia, hay un elemento vivencial irreductible en la filosofía que la hace actual, que garantiza su capacidad de asombro y creatividad. Conviene, pues, dar a la Historia de la Filosofía su justa dimensión en relación con el filosofar.

2) Entendiendo que la actividad y realización -no objetivada- de la Filosofía en absoluto procura estacionarse en un mero registro pasivo - y exacto- de lo que otros han hecho, sino de entablar un diálogo provechoso, acorde con lo que se discute como de lo que se plantea como problema. A las notas alrededor de una noción del quehacer filosófico, sumamosprovisionalmente- los caracteres que nos procuran una distinción en el ámbito de la compleja problemática demarcadora de la Filosofía y la Ciencia: (IV) Universalidad o Pantonomía, y 
autonomía filosófica. Orientada hacia la totalidad de las cosas, en tanto busca soluciones últimas, la pretensión universalista del filosofar se distingue respecto del saber especializado de la ciencia. Pantonomía que es la tensión opuesta al principio ascético de repliegue cauteloso que es la autonomía. (V)El enfoque sintético en contraste con la perspectiva analítica de la ciencia. (VI)Radicalidad. La Filosofía no se detiene ante supuestos, ni métodos, su inquietud la lleva a una problematización constante de la que no se escapa, incluso, la Ciencia. (VII) Y en tanto honda y radical la tarea del filosofar, integramos, el rasgo de la vocación perescrutadora, de la incoercible búsqueda de la verdad.

3) La Filosofía del Derecho, expresión que resulta apropiada a nuestra disciplina, y que evita prejuzgamientos en razón de su contenido, no es otra que la Filosofía misma ocupada desde una vocación integral y radical en las cuestiones jurídicas. Por ende, las notas que identifican su actividad alcanzan a los trabajos jusfilosóficos; y no sólo eso, el conjunto siempre abierto de la problemática filosófica deja su impronta, se proyecta en las indagaciones jusfilosóficas. Así, entre esas cuestiones centrales que avivan su tarea se ubican las preguntas sobre la temática axiológica. Las complejas interrogantes sobre los valores encuentran su espacio problematizador en la Filosofía del Derecho, más precisamente en el ámbito denominado Axiología Jurídica. Aunque no sería la única disciplina que encuentra su entroncamiento con la tarea jusfilosófica. Cabe añadir además, la complementariedad inquisitiva que promueve la propia esfera jurídica, cuando ahondando en su objeto, emprende la senda de radicales interrogantes, y que por tanto la acercan desde esa vía con la Filosofía, o mejor dicho la tornan filosófica. En cuanto a la denominación de Axiología Jurídica de nuestro estudio, similar al caso de la Filosofía del Derecho, convenimos en su acierto en razón de que se limita a presentar sin prejuzgar el problema o quehacer disciplinario.

\section{NOTAS:}

1 Miró QuesadA, Oscar. Lo que es la Filosofía. Lima, Imprenta Torres Aguirre, 1934, pp.78 .

2 Ferrater Mora, José. Filosofía. En Diccionario de Filosofía. T.I. Buenos Aires, Editorial Sudamericana, 1964, p. 662.

3 Salazar Bondy, Augusto. ¿Qué es filosofía?. Lima, 1967, pp. 8-9. Así también, inicialmente, precisa Johan Hessen: "Las definiciones esenciales que encontramos en la Historia de la Filosofía discrepan tanto, muchas veces, unas de otras, que parece completamente imposible extraer de ellas una definición esencial unitaria de la Filosofía". Teoría del conocimiento. 10ª ed. Buenos Aires, Ed. Losada, S.A., 1970, p.11.

4 Dilthey, Guillermo. La esencia de la Filosofía. Trad. Elsa Tabering. Buenos Aires, Imprenta López, 1994, pp. 89 y ss.

5 SALAZAR BONDY. Op. cit. pp. 9-10. 
6 HeIDEgGer, Martín. ¿Qué es esto, la filosofía?. (Trad. Víctor Li-Carrillo. Lima, Ed. de la U.N.M.S.M,1958, pp. 17-54.) En Para Iniciarse en Filosofía. Antología. Volumen I. José Carlos Ballón-Raymundo Prado-Juan Abugattas: Presentación, selección y notas. Lima-Perú, Universidad Nacional Mayor de San Marcos, 1993, pp.34-35.

7 Ibid. p. 35.

8 Mondolfo, Rodolfo. Problemas y Métodos de Investigación en la Historia de la Filosofía. $4^{\text {a }}$ ed. Argentina, Ed. Eudeba, 1969, p. 30. Presentando el caso de Descartes, señala Mondolfo, que E. Gilson en su libro: Index scholastico-cartésien, documenta las huellas dejadas por la escolástica en el pensamiento cartesiano.p.30.

9 SalaZAR Bondy, Augusto. Iniciación filosófica. $5^{\text {a }}$ ed. Lima, Ed. Mantaro, 2000, p. 22.

10 Miró Quesada C., Francisco. Ensayos de Filosofía del Derecho. Lima-Perú, Universidad de Lima, p.24.(notas).De Xavier Zubiri encontramos la siguiente expresión, sobre la relación de ambas disciplinas: "La ocupación con la historia de la filosofía no es, pues, una simple curiosidad; es el movimiento mismo a que se ve sometida la inteligencia cuando intenta precisamente la ingente tarea de ponerse en marcha a sí misma desde su última raíz. Por esto la historia de la filosofía no es extrínseca a la filosofía misma (...) La filosofía no es su historia; pero la historia de la filosofía es filosofía." En Prólogo a la Primera Edición. En MARÍAS, Julián. Historia de la Filosofía. 26a ed. Nuevamente ampliada. Madrid, Alianza Editorial, S.A., 1996, p. XXV.

11 MARÍAS. Op. cit. p.5.

12 MondOLFO. Op. cit. p. 65. El subrayado nos pertenece.

13 ARistóteles. Metafísica. Libro I. 982b-15. Trad. Valentín García Yebra, Madrid: Gredos, 1980. Asimismo, Platón nos decía en el diálogo Teeteto o de la Ciencia: "Muy propio del filósofo es el estado de tu alma: la admiración. Porque la filosofía no conoce otro origen que este, y bien dijo(pues era un entendido en genealogía) el que habló de Iris como hija de Taumante." Obras Completas. Trad. José Antonio Miguez. Madrid, Aguilar, p.901(155 $\mathrm{a} / 156 \mathrm{c})$.

\section{HeIDEGGER. Art.cit.}

15 SALAZAR BONDY. Iniciación filosófica. pp.22,23,24.

16 Dice el profesor David Sobrevilla, refiriéndose a la problemática que ocupa a la filosofía General y a la cultivada en el Perú, que la tendencia a historizar la filosofía, es decir a convertirla en historia de la filosofía, con lo que en verdad termina la filosofía. Se da actualmente en todo el mundo. Y el resultado es que algunos profesionales de la filosofía, aplastados por el peso de una historia monumental se siente incapaces de hacer filosofía, y son llamados tan sólo a hacer historia de la filosofía. Cf. La filosofía contemporánea en el Perú.1 a ed. Lima: Ed. Carlos Matta, 1996, pp.76, 79. A decir de Zubiri, "Precisamente, por tratarse de un saber radical y último, la filosofía se halla montada, más que otro saber alguno, sobre una tradición. De lo que se trata es que, aun admitiendo filosofías ya hechas, esta adscripción sea resultado de un esfuerzo personal, de una auténtica vida intelectual." Cit. en ZUBIRI, Xavier. Nuestra situación intelectual. 
17 Fernández Sessarego, Carlos. Bosquejo para una determinación ontológica del derecho. Tesis, U.N.M.S.M., 1950, Conclusión $2^{\mathrm{a}}$ pp.188-189. Para Karl Jaspers: "Toda Filosofía se define a sí misma por su realización. Lo que ella es no puede saberse más que por la experiencia; se ve, entonces, que ella es, al mismo tiempo, la actualización del pensamiento vivo y la reflexión sobre ese pensamiento, o la acción y el comentario de la acción" en Introduction a la Philosophie, trad. Jeanne Hersch, París, 1950, p.9,cit. ,REALE, Miguel. Filosofía del Derecho.Trad. Ángel Herreros Sánchez.Madrid, Ed. Priramide, 1979, nota 3, p.23.

18 García Morente, Manuel. Lecciones Preliminares de Filosofía.11a ed., México, Ed. Diana, 1964, p.2.

19 OrTEGa y Gasset, José. ¿Qué es filosofía?. Madrid, Ediciones de la Revista Occidente, $7^{a}$ ed.,1971, pp.250,251.

20 KANT, Inmanuel. Prolegómenos a toda metafísica del porvenir que haya de poder presentarse como una ciencia. Trad. Julián Besteiro. España, Ed. Sarpe, 1984, p.192. Además en el prefacio de la segunda edición de la Crítica de la razón pura tenemos: " $L a$ metafísica, aislado conocimiento especulativo de la razón, que nada toma de las enseñanzas de la experiencia y que sólo se sirve de simples conceptos(...)no tiene la dicha de haber podido entrar en el seguro camino de una ciencia(...).Así que el camino que se traza no es firme ni seguro, y mil veces es menester de nuevo rehacerlo, pues no conduce a adonde se deseaba llegar(...)Es necesario que nos convenzamos de que la marcha de ella ha sido hasta ahora incierta, el de un tanteo, y hecha, lo que es peor, por medio de simples conceptos.”Trad: José Perojo y José Rovira Armengol. Revisión del trad, Ansgar klein. Argentina, Ed. Orbis S.A., p.88.

21 Husserl, Edmundo. La filosofía como ciencia estricta. Trad. Elsa Tabernig. $2^{\mathrm{a}}$ ed. Buenos Aires, Ed. Nova, p.48.

[22] Wittgenstein, Luwig. Tractus Logico- Philosophicus. Trad. Enrique Tierno Galván. Madrid: Revista de Occidente, 1957, p.191.

[23] Jaspers, K. Filosofía y Ciencia, en "Balance y perspectiva". Trad. F. Vela, Madrid, Revista de Occidente, 1953, pp.144-145, cit., por Pucciarelli. Husserl y la actitud científica en Filosofía. En: Husserl, Edmundo. La filosofía como ciencia estricta, p.39. Pucciarelli considera entre los pensadores que plantean la delimitación a: Max Scheler, Karl Jaspers, Gabriel Marcel, Henri Bergson, Benedetto Crosse, Nicolás Abbagnano, León Chestov y Nicolás Berdiaeff. Vid.p.38 de la Op.cit.

[24] Prólogo a la Primera Edición de X. Zubiri en Marías, Julián. Op. cit. pp. XXVIII-XXIX.

[25] Popper, Karl R. La Lógica de la investigación científica. Trad. Víctor Sánchez de Savala. México, Red Editorial Americana, S.A.,1996, p. 34. Puntual también es la expresión: "Los positivistas suelen interpretar el problema de la demarcación de un modo naturalista: como si fuese un problema de la ciencia natural. En lugar de considerar que se encuentran ante la tarea de proponer una convención apropiada, creen que tienen que descubrir una diferencia -que existiría, por decirlo así, en la naturaleza de las cosas-entre la ciencia empírica por una parte y la metafísica por otra. Tratan constantemente de demostrar que la 
metafísica, por su misma naturaleza, no es sino parloteo absurdo-«sofistería e ilusión», como dice Hume, que deberíamos «arrojar a al fuego»"p.35.

[26] Bunge, Mario. Vigencia de la Filosofía. Pueblo Libre, Universidad Inca Garcilaso de la Vega, 1999, pp.49-50. En su decatupla conceptual de la ciencia particular, respecto a los supuestos filosóficos (G), se indica: "los científicos dan por sentado una cantidad de tesis de tipo filosófico. Por ejemplo, hay supuestos ontológicos, tales como que el mundo exterior existe independientemente del investigador; que el mundo exterior es legal es decir no hay milagros, hechos ilegales. Hay supuestos gnoseológicos, tales como el de la posibilidad de alcanzar la verdad, al menos parcial y aproximada. Finalmente, hay una ética del investigador: Los imperativos de la búsqueda de la verdad, de la coherencia y de la claridad; la propiedad común de los conocimientos, la promesa tácita de no usar el saber para dañar, etc. Quien viola estos preceptos morales no se considera un investigador científico propiamente dicho." pp. 27-29.

[27] Quintanilla PÉREZ-Wicht, Pablo. La pregunta por la demarcación en la filosofía de la ciencia actual. En La ciencia y el saber psiconálitico.1ª ed., Lima-Perú, Editor Juan Carlos Tafur, 1990.pp.29-33.

[28] Quintanilla PÉREZ-Wicht. Conocimiento, Demarcación y Elección de Teorías.

[29] QuinTANILLA PÉREZ-Wicht. Art. cit. p.13-14.

[30] HeSSEN. Op.cit.p.13. Afirma Icilio Vanni: "Y como cada ciencia o grupo de ciencias estudia un orden particular de hechos y de relaciones, ocurre en último término que la ciencia representa un saber fragmentario (...) La filosofía, pues, tiene un objeto específico, un contenido propio, que es la totalidad de las cosas; en una palabra, lo universal(...)De lo dicho se deduce que la filosofía representa el complemento o la integración de las ciencias. Toda ciencia singular, justamente porque estudia un orden particular de hechos, es impotente para tratar por sí los problemas generales comunes a todas las demás."cit. en Filosofía del Derecho. Trad. Rafael Urbano. Madrid, p.16.

[31] Bunge. Op. cit.p.28. La decatupla conceptual de la ciencia particular (CP) de Bunge: $\mathrm{CP}=<\mathrm{C}, \mathrm{S}, \mathrm{D}, \mathrm{G}, \mathrm{F}, \mathrm{B}, \mathrm{P}, \mathrm{A}, \mathrm{O}, \mathrm{M}\rangle$, se encuentra integrada por diez componentes, donde: $\mathrm{C}=$ comunidad; $\mathrm{S}=$ sociedad; $\mathrm{D}=$ dominio; $\mathrm{G}=$ supuestos filosóficos; $\mathrm{F}=$ fondo formal; $\mathrm{B}=$ fondo específico; $\mathrm{P}=$ problemática; $\mathrm{A}=$ fondo de conocimientos; $\mathrm{O}=$ objetivos; $\mathrm{M}=$ metódica. p. 31 .

[32] SALAZAR BONDY. ¿Qué es filosofía?. pp.22-23.

[33] MiRó QueSADA, Oscar. Lo que es la Filosofía. pp-33-34. Salazar Bondy en su tratado de Iniciación filosófica aclara más sobre este rasgo de la filosofía: "Las disciplinas filosóficas no deben ser consideradas sistemas de conocimientos independientes, a semejanza de las disciplinas científicas. No hay reflexión gnoseológica totalmente ajena al quehacer ontológico o antropológico(...)Esto ha llevado a decir, no sin razón, que la filosofía tiene sólo un gran asunto, que examina desde diversas perspectivas."

[34] Bochenski,J.M. Introducción al pensamiento filosófico. Barcelona, Ed. Herder, 1965, p.29. Señala Francisco Miró Quesada C.: La ciencia parte, siempre, de supuestos de los cuales no duda. "Cuando, por motivo de los problemas que genera su propio desarrollo, o por 
cualquier otra causa, la ciencia comienza a dudar de sus propios supuestos, se hace filosófica.” Ensayos de Filosofía del derecho. Lima, Universidad de Lima, pp. 13,29.

[35] Vid. ORTEGA Y GASSET, José. Lección V. En ¿Qué es Filosofía?.7ª ed., Madrid, Ed. de la Revista de Occidente, 1971.

[36] Epílogo de José Ortega y Gasset. En Marías. Op. cit. pp. 512-513.

[37] Ibid. pp.484, 485-486. Afirma Leo Strauss, que la filosofía es "esencialmente no la posesión de la verdad, sino la búsqueda de la verdad. El carácter distintivo del filósofo es que el sabe que no sabe nada, y que esta vista hacia nuestra ignorancia lo induce a buscar con todas sus fuerzas el conocimiento." Vid. What is Political Philosophy? And Other Essays. Chicago University Press, 1988, p.11. Subraya Bertrand Russell: "La dificultad que existe para descubrir la verdad no prueba que no haya una verdad a descubrir." Cf. Philosophical Essays. ed. Revisada, London, Allen \& Unwin, 1966, p.20, cit.,Frondizi, R.¿Qué son los valores?.3 $3^{a}$ ed., México, F.C.E., p.173. Decaimiento en la búsqueda de la verdad, que en el caso de los esfuerzos jusfilosóficos es notorio. Acierta, por ende, la denuncia cossiana respecto a los escasos esfuerzos en la epistemología jurídica, extensivo creemos, indudablemente, a los terrenos ontológicos y estimativos del Derecho. Cf. Prefacio. En Radiografía de la Teoría Egológica del Derecho. Buenos Aires, Depalma, 1987, pp.XIXIII.

[38] Cossio, Carlos. La Plenitud del Orden Jurídico y la Interpretación Judicial de la Ley. Buenos Aires, Ed. Losada, S.A., 1939, pp.183-184,186-188. Según, Daniel E. Herrendorf, "Ningún error es más caro a las ciencias que asumir ellas mismas la definición entitativa de los objetos de su estudio; o la busca de su cientificidad; o la sustantividad de la gnoseología. El científico conoce: no se detiene en cuestionar si el conocimiento es posible." Introducción a la Fenomenología Egológica. En Radiografía de la Teoría Egológica del Derecho. Buenos Aires, Depalma, 1987, pp. 14-15. A decir de Reale, hay dos prejuicios, equivalentes; uno, pretende que la Filosofía sea solamente un reflejo de las ciencias y el otro es pensar que la Filosofía posee mayor dignidad que la de las propias ciencias. El problema de la dignidad, carece de sentido; cada uno de estos tipos de saber posee, su propia esfera, su propia valía. No existe una jerarquía de méritos entre el científico y el filósofo. La Filosofía se acerca a la Ciencia para criticarla: pero esto quiere decir que sea superior, en valor, a la propia Ciencia, a la que hay que reconocer la autonomía que le es propia. Son campos de investigación distintos, sin que existan, entre ellos, vínculos jerárquicos que lleven a que la Filosofía sea una ancilla scientiate, ni que la Ciencia sea algo subordinado a la Filosofía. Son, por el contrario, conocimientos que marchan en mutua dependencia, de tal suerte que no es posible filosofar, en una época dada, con abstracción o desconocimiento total de los resultados de la Ciencia contemporánea. Cf. REALE. Filosofía del Derecho. pp. 43-44.

[39] ReCASÉns Siches, Luis. Filosofía del Derecho. En Enciclopedia Jurídica OMEBA. Tom.XII. Buenos Aires, Driskill, S.A., 1994, p.229.

[40] AlZamora Valdez, Mario. La Filosofía del Derecho, Lima, 1976, p.13.

[41] LÓPEZ DE OÑATE, Flavio. Filosofía del Derecho. Trad. Alberto S. Bianchi, Buenos Aires, Ed. Jurídicas Europa- América- Bs. As., 1961, pp.27-28. Asimismo, anotase de Falchi: "Es tan íntima la conexión entre la filosofía general y sus especificaciones, que éstas no podrían concebirse sin referencia a la totalidad del sistema del que extraen los presupuestos y al que 
concurren con sus conclusiones." Falchi, A.Filosofia proipedeutica. Introduzione alle filosofia particolari, Torino, 1941, p.116, cit. por López de Oñate. Filosofía del Derecho. p.31.

[42] Martínez Paz, Enrique. Tratado de Filosofía del Derecho. Córdoba, Ed. Litvack, 1946,p.50. Para R. Stammler- en su Tratado de Filosofía del Derecho- la procedencia del uso de la expresión "Filosofía del Derecho", parece proceder de Hugo, indicando para tal efecto, su Curso de Derecho Civil, esp. II: Tratado de Derecho Natural o Filosofía del Derecho positivo, 1797. Antes de él- precisase- el título de los libros que se escribían sobre esta materia respondía a la orientación de las doctrinas, o se le adscribía como tema simplemente el Derecho Natural. Vid. Tratado de Filosofía del Derecho. $1^{\text {a }}$ ed., Madrid, Ed. Reus, S.A., 1930, p.1. En el caso de la Universidad San Marcos, a decir de Juan Bautista de Lavalle, las vacilaciones y divergencias acerca de la naturaleza, el contenido, y el método del curso, alcanzaron a la propia denominación, a saber, entre ellas: 'Derecho Natural', 'Principios Generales de Legislación', 'Enciclopedia Jurídica', y 'Filosofía del Derecho'. Vid. DE Lavalle, Juan Bautista. Filosofía del Derecho y Docencia Jurídica. En Revista de Derecho y Ciencia Política. Año II, T.III, Lima, 1939, pp.568-569.

[43] ReALE. Filosofía del Derecho. pp. 24-25. En esa vía, para Martínez Paz: "La filosofía, hemos expresado, es un saber de lo universal; lo particular no puede ser objeto de la filosofía, no cabe una filosofía de lo particular. Si se mira el derecho objetivamente, desde el punto de vista de las leyes y de los principios positivos, no es posible llegar a una filosofía."cit. Tratado de Filosofía del Derecho. Córdoba(R.A.), Ed. Litvack, 1946, p.22.

[44] Sobre la diferenciación entre la Gnoseología y la Epistemología, observa Ferrater Mora: "no siempre es fácil distinguir entre problemas de teoría del conocimiento en general y problemas de teoría del conocimiento científico, es inevitable que haya vacilación en el uso de los términos". cit. en Diccionario de Filosofía. Tom.I. p.759.

[45] Stammler, R. Tratado de Filosofía del Derecho. pp.3-4. Precisa el profesor Fernández Sessarego: que justamente una epistemología basada en Kant constituye la obra de Stammler, quién aplica el programa criticista para solucionar el duelo entre razón e historia. Siguiendo a Kant establece la diferencia entre concepto e idea. Al respecto, véase, Bosquejo...(Tesis)pp. 52-55.Una relación de obras e índice bibliográfico sobre del profesor de la Universidad de Berlín, a cargo del profesor argentino Ernesto Garzón Valdés, y confeccionado gracias a la información de doscientas veintinueve bibliotecas y archivos de universidades y centros de investigación jurídica del país y del extranjero, se encuentra en la versión española de Wesen des Rechtes und der Rechtwissenschaft (La esencia del Derecho y de la ciencia del Derecho). Códoba (R.A.), Imprenta de la Universidad, 1958, pp.159-180. Entre otras obras trad. esp.de R. StAmmler se tiene: Cuestiones fundamentales de Filosofía y Derecho. En Rev. De Derecho Privado, España, 15 de jun de 1922, Año X, n¹05, pp.161-170; La génesis del Derecho. Rad. de W. Roces. Madrid, Calpe, 1925.

[46] Vanni. Op. cit. p. 22. De la Lezioni de Filosofia del Diritto del maestro italiano, como sabemos, existe traducción al castellano y notas a cargo del profesor Juan Bautista de Lavalle.

[47] HeIDEGger, Martín. El Ser y el Tiempo. Trad. José Gaos. 2ª ed. México, Ed. FCE, 1988, pp.20-21.

[48] García Morente. Op.cit.p.50. 
[49] Fernández SesSAREgo. El Derecho como libertad. $2^{\mathrm{a}}$ ed El derecho como libertad.2 ${ }^{\mathrm{a}}$ ed., Universidad de Lima, 1994, pp.45-46. Coincidiendo en el carácter fundamental de la ontología, tenemos también a Legaz y Lacambra: "El problema ontológico, pues, tiene carácter fundamental y fundante, porque condiciona el planteamiento de los otros problemas de la Filosofía y la ciencia del Derecho. En efecto, los valores jurídicos-la justicia, ante todo-son valores del ser jurídico, y el modo de ser del Derecho determina su concepto y el sistema de las categorías conceptuales en que se expresan las estructuras fundamentales de la realidad jurídica." cit. en Filosofía del Derecho. Barcelona, Bosch, 1978, p.38.

[50] ReCASÉns SicheS. Vida Humana, Sociedad y Derecho. $2^{a}$ ed. pp. 379-380.

[51] Kelsen, Hans. Teoría Pura del Derecho. Lima. Ed. Wisla, 1987, p.46 y pp. 44-45. Aunque en su Introducción a la Teoría Pura del Derecho $\left(3^{\mathrm{a}}\right.$ ed. Trad. del inglés Emilio O. Rebasa, Lima, 2001), ya no tan radical en su posición expresa: "el Derecho debe distinguirse de la justicia. Un enunciado que describa al Derecho no debe implicar ningún juicio acerca del valor moral de la ley, es decir, sobre su justicia o injusticia, lo que por supuesto no excluye el postulado de que el Derecho deba ser justo. Sin embargo, en virtud de que no sólo existe una justicia, sino diferentes e inclusive contradictorios ideales de justicia, el postulado no debe plantearse sin especificar cuál de estas muchas justicia se refiere."pp. 60-61. Entre otros textos de Kelsen que abordan el tema estimativo Vid.: What is Justice?. En California Law Review, vol.45, N4, 1957; La idea del Derecho Natural y otros Ensayos. Buenos Aires, LOSADA,1946; Metamorfosis de la idea de justicia. En Rev. De la Escuela de Jurisprudencia. T- IX, oct-dic, $\mathrm{n}^{\circ} 44$, México, 1949. Sobre el relativismo axiológico de Kelsen, véase, RECASÉnS SICHES, Luis. Panorama del Pensamiento Jurídico en el siglo XX. Tom I, $1^{\text {a }}$ ed.,México, Ed. Porrua, S.A., 1963, pp.189 y ss. De la posición kelseniana apunta Reale: "En cuanto a la teoría de Kelsen, según Josef Kunz, se podría hablar de tricotomía implícita, aunque tal vez sea preferible denominarla «tridimensionalismo metodológico-negativo», pues en su sistema, efectivamente, sólo tiene carácter jurídico la Ciencia del Derecho como estudio lógico-sistemático de normas, independiente siempre del carácter metajurídico tanto de la Teoría de la Justicia como de la Sociología Jurídica." Cf. Teoría Tridimensional del Derecho. p.56. Sobre este autor, conviene mencionar, además, el sobresaliente ensayo de Carlos Cossio. Hans Kelsen. El jurista de la época contemporánea. En La valoración jurídica y la ciencia del Derecho. Buenos Aires, Ed. Depalma, 1954, pp.135-147.

[52] Cossio, Carlos. Estimativa Jurídica. En Revista del Colegio de Abogados de Buenos Aires. Año XXI-T.XX-N²4, julio-agosto 1992, pp.513-515.

[53] FERnÁNDEZ SeSSAREGO. Bosquejo...p.199-202. Se refleja, en esta apreciación, también, su concepción tridimensional del Derecho, que como sabemos, adelantase a la teoría tridimensional de Miguel Reale. En razón de que sus ideas se plasmaron en 1950, en la tesis para optar el grado de bachiller en Derecho. Investigación ésta, pensada y escrita durante el período 1946-1949; por su parte, el jusfilósofo brasileño presentó en 1953, en su Filosofía do Direito, la versión orgánica de su teoría. Al respecto, véase, entre otros tratados: GARCíA Belaunde, Domingo. A José León Barandiarán, homenaje a su ciencia, a su magisterio, a su amistad. En el Libro homenaje a José León Barandiarán. Lima, Ed. Cuzco, 1985, p.257; y la Nota preliminar al texto El Derecho como libertad de Fernández Sessarego, pp.36-37.

[54] Miró Quesada C., Francisco. Sobre el Derecho Justo. En Ensayos de Filosofía del Derecho. Lima-Perú, Universidad de Lima, pp.50-51. En otro parte del mismo ensayo, plantea: "La única manera de no proceder arbitrariamente es, pues, considerar a todos los 
hombres como fines en sí y no como medios. Toda reificación, toda alineación, queda así excluida. Cada hombre es considerado como una exigencia de realizar plenamente sus posibilidades, con la sola limitación de no impedir la realización de las posibilidades de los demás. Una vez fundada racionalmente la ética, se pasa directamente a la fundamentación racional del derecho. El derecho racional o justo es el derecho no arbitrario. Una sociedad justa es una sociedad organizada mediante un sistema de leyes que haga imposible el imperio de la arbitrariedad. Justicia, razón y no arbitrariedad son sinónimos en el mundo del derecho."p.54. Además, véase Fundamentación Filosófica de los Derechos Humanos. En Ensayos..., pp.13-26. Así como La axiología o teoría de los valores, en Para iniciares en la Filosofía. Lima-Perú, Universidad de Lima, 1981, p.139 y ss. Para un estudio crítico del aporte estimativo de Miró Quesada C., Cf. de Fernández Sessarego, Carlos. La concepción del Derecho de Francisco Miró Quesada. En Lógica, Razón y Humanismo. La obra filosófica de Francisco MIRÓ QuESADA C.(Editores David Sobrevilla/ Domingo García Belaunde)Lima, Universidad de Lima,1992, pp.219-261, 411-413.

[55] Miró Quesada C., Francisco. El Derecho justo. En Ius et Veritas. Lima-Perú, Universidad Católica, 1994, N,pp.45-48.

[56] LóPEZ Ruf, Pablo. Moral y Derecho en Dworkin. En Anuario de Filosofía Jurídica y Social. N 11, Buenos Aires, Abeledo Perrot, 1991, pp.141-142.

[57] Dworkin, R. Los Derechos en serio, Los casos difíciles. Barcelona, Ariel, 1989, p. 146. Entre otros textos de este autor se ubican: Foundations of Liberal Equality. Hay traducción castellana, intitulada Ética privada e igualitarismo político. Trad.Antoni Doménech, España, Ed. Piados, 1993. Asimismo: Taking Rights Seriously. Londres, Duckworth, 1977; Law's Empire. Cambridge, Harvard University Press, 1986; The Ethical Basis of Liberal Equality, Ethics and Economics, Universidad de Siena, 1991; Equality, Democracy, and Constitution, Alberta Law Review, vol. XXVIII, n², 1990.

[58] RAWLS, John. Teoría de la Justicia (A Theory of Justice). $2^{\mathrm{a}}$ ed. en español, México, F.C.E., 1997, p.17. Como bibliografía inicial de este autor cabe citar: Political Liberalism. Nueva York, Columbia University Press, 1993; Law of Peoples, en S. Shute \& S. Hurley(comps.), On human Rights. The Oxford Amnesty Lectures, Oxford, Oxford University Press, 1993. Sobre este autor: Vid GARGARELla, Roberto. Las Teorías de la justicia después de Rawls .España, Ed. Piados, 1999; La Justicia: John Rawls contra la tradición de la filosofía política. En Bloom, Allan. Gigantes y Enanos. La tradición ética y política de Sócrates a John Rawls. España, Ed. Gedisa, 1999, pp.407-446. Para un conocimiento del debate entre John Rawls y Jürgen Habermas, véase, Jürgen Habermas/ John Rawls. Debate sobre el liberalismo político.(Introducción de Fernando Vallespín)Barcelona-Buenos AiresMéxico.Ed. Piados, 1998.

[59] MACINTYRE, Alasdair. La Justicia como virtud: conceptos cambiantes. En Tras la Virtud (After Virtue). Trad.Amelia Valcárcel.Barcelona, Ed. Crítica, 1987, pp.305-308. De Macintyre, entre sus obras se cuenta: Three Rival Versions of Moral enquiry. Encyclopedia, Genealogy and Tradition. University of Notre Dame Press, 1990.

[60] FERNÁNDEZ SESSAREGO. Bosquejo...pp.90-91.

[61] Ascoli, Max. La interpretazione delle leggi. Roma, Athenaeum, 1928, p.10, cit. por Cossio, Carlos. La valoración jurídica y la ciencia del derecho. Buenos Aires: Ed. Arayú, 
1954, p.30. Argumenta Miró Quesada C., que resulta imposible desvincular el mundo de los valores del Derecho. De ahí la relación de éste con la Filosofía. Es justamente el problema de la justicia, de la dignidad humana, de la hermenéutica, cuestiones que rebasan el ámbito científico. En consecuencia es muy importante que los juristas tengan formación filosófica. Cf. Intervención del Profesor Francisco Miró Quesada en el Acto de Presentación del Libro "Derecho de las Personas" del Profesor Carlos Fernández Sessarego. En Estudios Jurídicos en honor de los profesores Carlos Fernández Sessarego y Max Arias Schreiber Pezet. LimaPerú, Ed. Cultural Cuzco, S. A., 1988, p.418.

[62] ReCASÉns SiCHES, Luis. Estimativa Jurídica. En Enciclopedia Jurídica OMEBA, Tom.XI, p. 166.

[63] Ibid. p.165.

[64] Ferrater Mora, José. Diccionario de Filosofía. Tom. I. Barcelona, Ed. Ariel, S.A., 1994, p.287.

(*) Egresado de la Maestría en Filosofía de la Universidad Nacional Mayor de San Marcos. Miembro fundador, Director y Miembro honorario de la Revista Jurídica Cathedra, Espíritu del Derecho; Ex Presidente de Cathedra Asociación Civil. 